\title{
Influence of SiC Surface Preparation on Homoepitaxial Growth; X-ray Reflectometric Studies
}

\author{
K. Mazur ${ }^{a}$, W. Wierzchowski ${ }^{a}, \mathrm{~K} \cdot \mathrm{Wieteska}^{b}, \mathrm{~W} \cdot \operatorname{Hofman}^{a}, \mathrm{H} \cdot \mathrm{Sakowska}^{a}$, \\ K. Kościewicz ${ }^{a}$, W. Strupiński ${ }^{a}$ And W. GraefF ${ }^{c}$ \\ ${ }^{a}$ Institute of Electronic Materials Technology, Wólczyńska 133, 01-919 Warsaw, Poland \\ ${ }^{b}$ Institute of Atomic Energy Polatom, 05-400 Otwock-Świerk, Poland \\ ${ }^{c}$ HASYLAB at DESY, Notkestr. 85, 22-603 Hamburg, Germany
}

\begin{abstract}
X-ray reflectometric and diffraction topographic methods were applied for examination of $4 \mathrm{H}$ and $6 \mathrm{H}$ silicon carbide substrates finished with various regimes, as well as, silicon carbide epitaxial layers. The investigations indicated a very good quality of the substrate surfaces finished with the process established at the Institute of Electronic Materials Technology, which provided the surface roughness $\sigma=0.55 \pm 0.07 \mathrm{~nm}$ for $4 \mathrm{H}-\mathrm{SiC}$ wafers. These values were better than those of substrate wafers offered by many commercial producers. The surface roughness was decreased during the initial high temperature etching to $\sigma=0.22 \pm 0.07 \mathrm{~nm}$. A relatively good structural quality was confirmed in the case of $4 \mathrm{H}$ epitaxial wafers deposited on the substrates prepared from the crystals manufactured at the IEMT, with the $8^{\circ}$ off-cut from the main (001) plane.
\end{abstract}

PACS numbers: 61.05.cm, 61.72.Ff, 61.72.up

\section{Introduction}

The technology of modern high temperature electronic materials often includes the epitaxial deposition of silicon carbide $(\mathrm{SiC})$ on the $\mathrm{SiC}$ substrates. The essential for the applications is achieving a high perfection of the deposited layers, especially the elimination of micropipes and basal plane dislocations. The last ones are very dangerous in high-voltage devices in view of their possible migration associated by the formation of large stacking faults.

Deposition of perfect epitaxial layers is even more dependent on the appropriate finishing of the surface, than on the concentration of defects in the substrate crystals. Nevertheless, the last factor can not be to any extent neglected $[1,2]$. Obtaining of the suitably good quality of the surface finishing is otherwise very difficult in the case of silicon carbide, as it is a very hard material and resistant against many of chemical reagents. Several methods of surface finishing were proposed [1-5]. The influence of defects present in the bulk of substrate wafers on the perfection of deposited homoepitaxial layers of silicon carbide have been discussed [6-9]. It should be noted that the quality of silicon carbide epitaxial layer is also strongly affected by the high temperature etching in the mixture of hydrogen and gaseous propane usually applied at the first stages of the epitaxial process.

In the present work, the X-ray reflectometric investigations were performed for a number of samples both of $4 \mathrm{H}-$ and $6 \mathrm{H}-\mathrm{SiC}$ polytypes prepared using finishing regimes developed at the Institute of Electronic Materials Technology (IEMT). The structural perfection of epitaxial layers and of substrate wafers was also controlled by synchrotron X-ray diffraction topography realized both in white and monochromatic beams at HASYLAB.

\section{Experimental}

The specular reflectometric investigation were performed by means of adapted a high resolution X-ray diffractometer arrangement [10]. The important point of the present experimental setup was the use of the vertical linear focus from a standard diffractometric X-ray tube. This enabled an effective separation of the characteristic $\mathrm{CuK} \alpha_{1}$ line by means of a single channel-cut Ge monochromator, and obtaining a high intensity of the probe beam. The experimentally evaluated beam divergence did not exceed 8 angular seconds. As the reflectometric measurements were performed in the vicinity of the critical angle of total reflection $\theta_{c}$ given by the formula

$$
\theta_{\mathrm{c}}=\left(\left|\chi_{0}\right|\right)^{1 / 2}
$$

(where $\chi_{0}$ is zero Fourier component of the dielectric susceptibility), the illuminated surface area was approximately $8 \times 14 \mathrm{~mm}^{2}$. The values of the surface roughness were evaluated by fitting of theoretical reflectivity curves to the experimental ones, by means of REFSIM program.

The defect structure of $\mathrm{SiC}$ epitaxial layers was investigated by means of synchrotron diffraction topography at the F1 and E2 experimental stations of DORIS III in 
HASYLAB. Both the white and monochromatic beams $(\lambda=0.1115 \mathrm{~nm})$ topographic methods were used in the Bragg geometry. The section topography (with the application of a fine $5 \mu \mathrm{m}$ slit and the glancing angle of $5^{\circ}$ ) enabled the indication of volume character of the defect distribution. High sensitivity to strains associated with small inclusions and dislocation loops was provided by monochromatic beam topography.

The silicon carbide epitaxial layers were deposited at the IEMT with the chemical vapor deposition method (CVD) using the epitaxial reactor manufactured by Aixtron [11]. The epitaxial reactor was also used for preparation of preetched substrates by performing only the initial stage of the epitaxial process. Some of the substrates were cut from bulk silicon crystals grown at the IEMT using the physical vapor transport (PVT) method.

\section{Results and discussions}

The X-ray specular reflectivity measurements were performed with $\theta / 2 \theta$ scans for the samples of $6 \mathrm{H}$ and $4 \mathrm{H}$ polytype from $\mathrm{SiC}$ substrate wafers cut with $4^{\circ}$ off-cut, $8^{\circ}$ off-cut and $0^{\circ}$ off-cut (i.e. on-axis) with respect to the (001) plane. The samples were prepared as epi-ready substrates by commercial manufacturers SiCrystal and Cree Inc., as well as, by the IEMT. The obtained X-ray reflectivity curves for $4^{\circ}$ and $0^{\circ}$ off-cut $4 \mathrm{H}-\mathrm{SiC}$ substrates are presented in Fig. 1. The values of the surface roughness $\sigma$ evaluated from the best fit of theoretical curves are slightly higher than $2 \mathrm{~nm}$, namely: $\sigma=2.09 \pm 0.05 \mathrm{~nm}$ for $4 \mathrm{H}-\mathrm{SiC}$ wafer with $0^{\circ}$ off-cut, $\sigma=2.16 \pm 0.05 \mathrm{~nm}$ for $4 \mathrm{H}-\mathrm{SiC}$ with $8^{\circ}$ off-cut and $\sigma=2.17 \pm 0.05 \mathrm{~nm}$ for $4 \mathrm{H}-\mathrm{SiC}$ with $4^{\circ}$ off-cut. The evaluated values of the surface roughness for all examined $\mathrm{SiC}$ substrates and epitaxial layers are listed in Table.

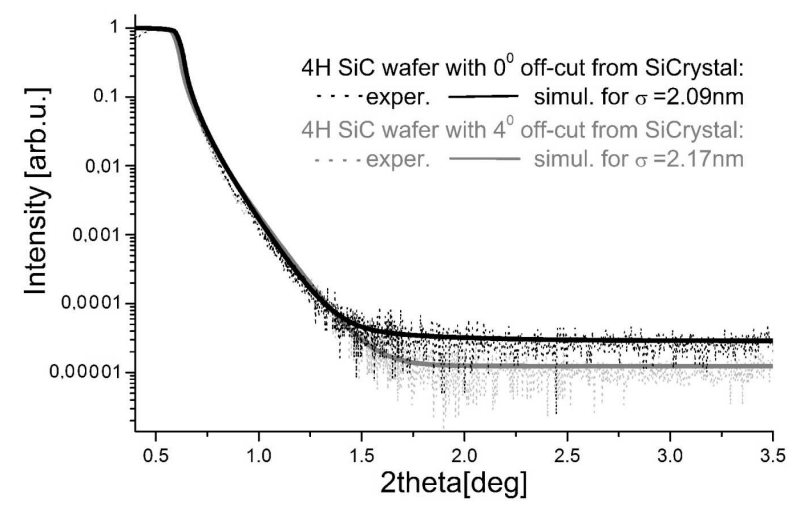

Fig. 1. The measured and simulated X-ray reflectivity curves for substrate wafers manufactured by SiCrystal with: $4^{\circ}$ off-cut and the evaluated roughness $\sigma=$ $2.16 \pm 0.05 \mathrm{~nm}$, and $0^{\circ}$ off-cut (on-axis) and the evaluated roughness $\sigma=2.09 \pm 0.05 \mathrm{~nm}$.

It was indicated that in the case of $4 \mathrm{H}$ homepitaxial layers the evaluated values of the layer roughness can be significantly higher than those of substrates. As may

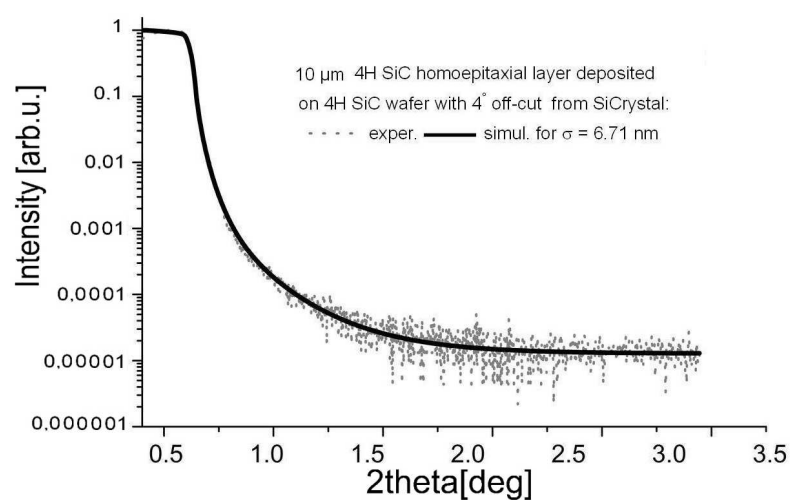

Fig. 2. The measured and simulated X-ray reflectivity curves for the sample consited of $4 \mathrm{H}-\mathrm{SiC}$ epitaxial layer with the thickness of $10 \mu \mathrm{m}$, on $4 \mathrm{H}-\mathrm{SiC}$ wafer with $4^{\circ}$ off-cut. The evaluated roughness of the epitaxial layer was $\sigma=6.71 \pm 0.05 \mathrm{~nm}$.

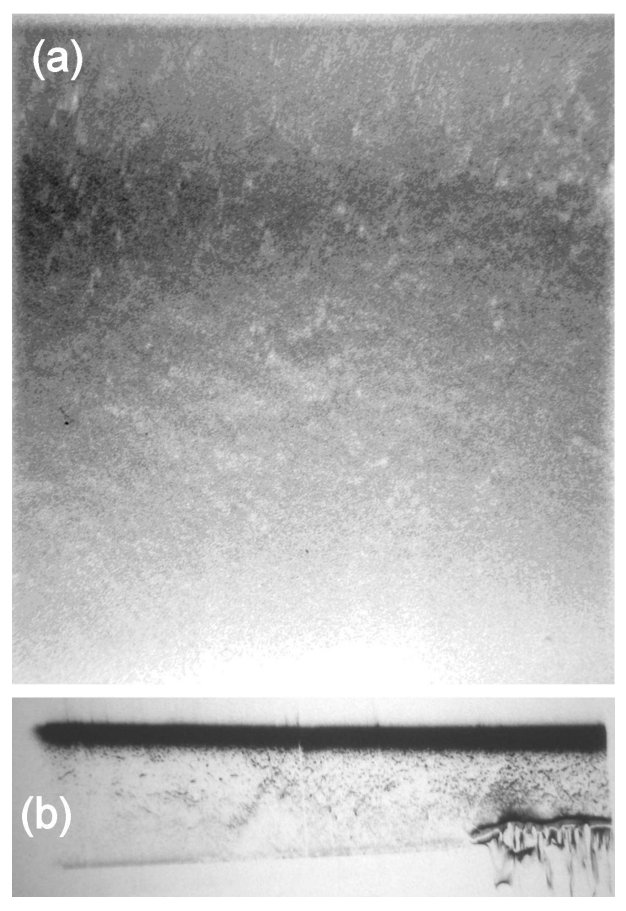

Fig. 3. Synchrotron white beam projection (a) and section (b) topographs of the same (as in Fig. 2) $4 \mathrm{H}-\mathrm{SiC}$ epitaxial layer grown on $4 \mathrm{H}-\mathrm{SiC}$ substrate (manufactured by SiCrystal) with $4^{\circ}$ off-cut. The grain-like contrast is interpreted as the result of the not perfect finishing of the surface.

be seen in Fig. 2, for the heavily nitrogen doped layer (to $10^{18} \mathrm{~cm}^{-3}$ ) deposited on the substrate wafer with $4^{\circ}$ off-cut manufactured by SiCrystal, the roughness of the deposited layer was $\sigma=6.71 \pm 0.05 \mathrm{~nm}$, while the roughness of the substrate was $\sigma=2.17 \pm 0.05 \mathrm{~nm}$. For this layer, the synchrotron white beam projection topograph, shown in Fig. 3, has revealed a grain-like contrasts, most probably corresponding to a high concentration of struc- 
tural defects. These defects are less visible in the Bragg-case section topograph, shown in Fig. 3b, which revealed many defects (mainly dislocations) present in the substrate. It indicates that commercial substrates often contain some imperfections of surface finishing, causing the generation of defects in deposited epitaxial layers. Fig- ure 4 illustrates the defects caused by the not perfect surface finishing in $10 \mu \mathrm{m}$ epitaxial layer on $\mathrm{SiC}$ substrate with $8^{\circ}$ off-cut manufactured by SiCrystal. Namely, the synchrotron images revealed dislocations with low density (dominantly of screw type) and some defects generated at residual scratches on the surface of the substrate.

The evaluated values of the surface roughness of the examined silicon carbide substrate wafers

TABLE and $4 \mathrm{H}-\mathrm{SiC}$ homoepitaxial layers.

\begin{tabular}{|c|c|c|c|c|c|c|}
\hline $\begin{array}{c}\text { Sample } \\
\text { No. }\end{array}$ & $\mathrm{SiC}$ polytype & $\begin{array}{c}\text { Substrate } \\
\text { manufacturer }\end{array}$ & $\begin{array}{l}\text { Off-cut } \\
\text { [deg] }\end{array}$ & Special treatment & $\begin{array}{c}\text { Evaluated } \\
\text { surface } \\
\text { roughness } \\
\sigma[\mathrm{nm}] \\
\end{array}$ & $\begin{array}{c}\text { Thickness of the } \\
\text { epitaxial layer } \\
{[\mu \mathrm{m}]}\end{array}$ \\
\hline 1 & $4 \mathrm{H}-\mathrm{SiC}$ & SiCrystal & 8 & & $2.16 \pm 0.05$ & \\
\hline 2 & $4 \mathrm{H}-\mathrm{SiC}$ & SiCrystal & 0 & & $2.09 \pm 0.05$ & \\
\hline 3 & $4 \mathrm{H}-\mathrm{SiC}$ & SiCrystal & 4 & & $2.17 \pm 0.05$ & \\
\hline 4 & $4 \mathrm{H}-\mathrm{SiC}$ & SiCrystal & 8 & pre-etching I-type & $2.19 \pm 0.05$ & \\
\hline 5 & $4 \mathrm{H}-\mathrm{SiC}$ & SiCrystal & 8 & pre-etching II-type & $0.22 \pm 0.07$ & \\
\hline 6 & $4 \mathrm{H}-\mathrm{SiC}$ & IEMT & 8 & $\begin{array}{c}\text { additional } \\
\text { electrochemical } \\
\text { polishing }\end{array}$ & $0.55 \pm 0.07$ & \\
\hline 7 & $6 \mathrm{H}-\mathrm{SiC}$ & Cree Inc. & 0 & & $0.86 \pm 0.05$ & \\
\hline 8 & $6 \mathrm{H}-\mathrm{SiC}$ & IEMT & 0 & & $1.88 \pm 0.05$ & \\
\hline 9 & $6 \mathrm{H}-\mathrm{SiC}$ & IEMT & 0 & & $1.78 \pm 0.05$ & \\
\hline 10 & $6 \mathrm{H}-\mathrm{SiC}$ & SiCrystal & 0 & & $1.21 \pm 0.05$ & \\
\hline 11 & $6 \mathrm{H}-\mathrm{SiC}$ & IEMT & 4 & $\begin{array}{c}\text { additional } \\
\text { electrochemical } \\
\text { polishing }\end{array}$ & $0.85 \pm 0.05$ & \\
\hline 12 & $4 \mathrm{H}-\mathrm{SiC}$ & IEMT & 8 & $\begin{array}{c}\text { additional } \\
\text { electrochemical } \\
\text { polishing } \\
\text { pre-etching II-type }\end{array}$ & $1.14 \pm 0.05$ & 20 \\
\hline 13 & $4 \mathrm{H}-\mathrm{SiC}$ & SiCrystal & 4 & pre-etching I-type & $6.71 \pm 0.05$ & 10 \\
\hline
\end{tabular}

Our study of the initially pre-etched sample, obtained with the use of epitaxial generator, has revealed a significant difference of the surface quality for various pre-etching regimes, as it is also shown in Table. A properly chosen pre-etching regime improved the substrate surface roughness up to $\sigma=0.22 \pm 0.07 \mathrm{~nm}$.

In order to receive a perfect epitaxial layer, an improved finishing process of the substrate surface and the new pre-etching process before the epitaxial process were established at the IEMT. The application of more fine surface lapping decreased the surface roughness to $0.85 \mathrm{~nm}$ for $6 \mathrm{H}-\mathrm{SiC}$ with $4^{\circ}$ off-cut, as it is illustrated in Fig. 5. This value was close to the surface roughness of $6 \mathrm{H}-\mathrm{SiC}$ on-axis substrates manufactured by Cree Inc. Additional finishing with electrochemical treatment
(ECMP) for $4 \mathrm{H}-\mathrm{SiC}$ sample with $8^{\circ}$ off-cut from the IEMT resulted in the surface roughness $\sigma=0.55 \mathrm{~nm}$.

The epitaxial layer with a thickness of $20 \mu \mathrm{m}$ was deposited after pre-etching process on the $4 \mathrm{H}-\mathrm{SiC}$ substrate wafer with $8^{\circ}$ off-cut which was manufactured at the IEMT. The evaluated value of the surface roughness was $\sigma=1.14 \pm 0.05 \mathrm{~nm}$. The synchrotron white beam projection (a) and section (b) topographs of this sample are presented in Fig. 6, indicating a relatively good perfection of the layer, as it is shown by individual dislocations and some pipe-formed cavities. However, it should be noted that the PVT generator used at the IEMT provided crystals containing a higher concentration of defects than in the case of crystals grown by SiCrystal and Cree Inc. 


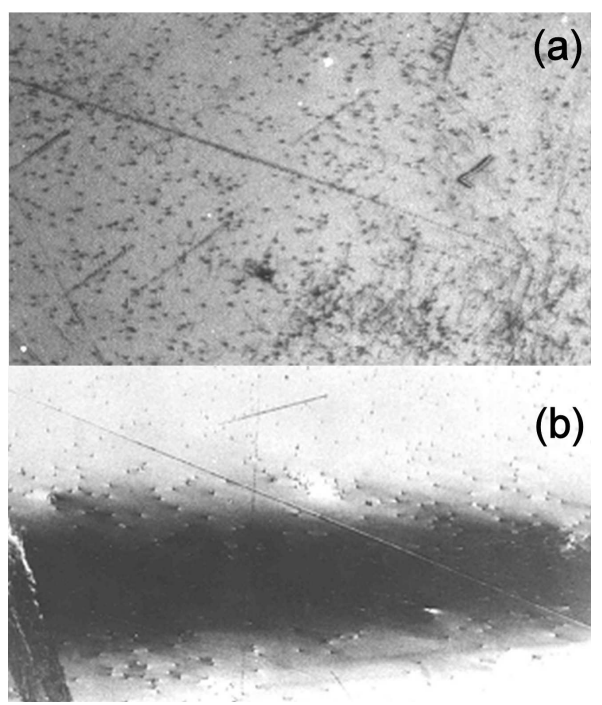

Fig. 4. The back reflection white beam projection synchrotron topograph (a) and the monochromatic beam topograph (b) in (004) plane of $10 \mu \mathrm{m}$ thick epitaxial layer on $4 \mathrm{H}-\mathrm{SiC}$ wafer with $8^{\circ}$ off-cut manufactured by SiCrystal, revealing dislocations and some defects caused by scratches on the surface of the substrate.

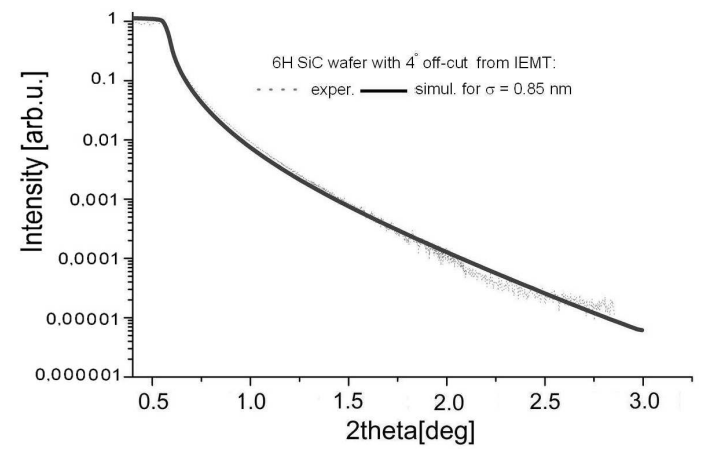

Fig. 5. The measured and simulated X-ray reflectivity curves for $6 \mathrm{H}-\mathrm{SiC}$ substrate wafer with $4^{\circ}$ off-cut manufactured at the IEMT, with the evaluated roughness of the surface $\sigma=0.85 \pm 0.05 \mathrm{~nm}$.

\section{Conclusions}

X-ray reflectometric investigations were performed on numerous samples both of $4 \mathrm{H}$ and $6 \mathrm{H}$ polytypes prepared by commercial manufacturers SiCrystal and Cree Inc., and at the IEMT. The investigations confirmed a very good quality of the surface finishing with the processes actually developed at the IEMT providing, in case of $4 \mathrm{H}$ wafers, the surface roughness $\sigma=0.55 \pm 0.07 \mathrm{~nm}$. This value was better than those of substrate wafers offered by many commercial producers. A relatively good structural quality was confirmed in the case of $4 \mathrm{H}$ epitaxial layers deposited on wafers prepared from the best crystals with the $8^{\circ}$ off-cut from (001) plane, manufactured at the IEMT.

It was indicated that surface finishing was improved

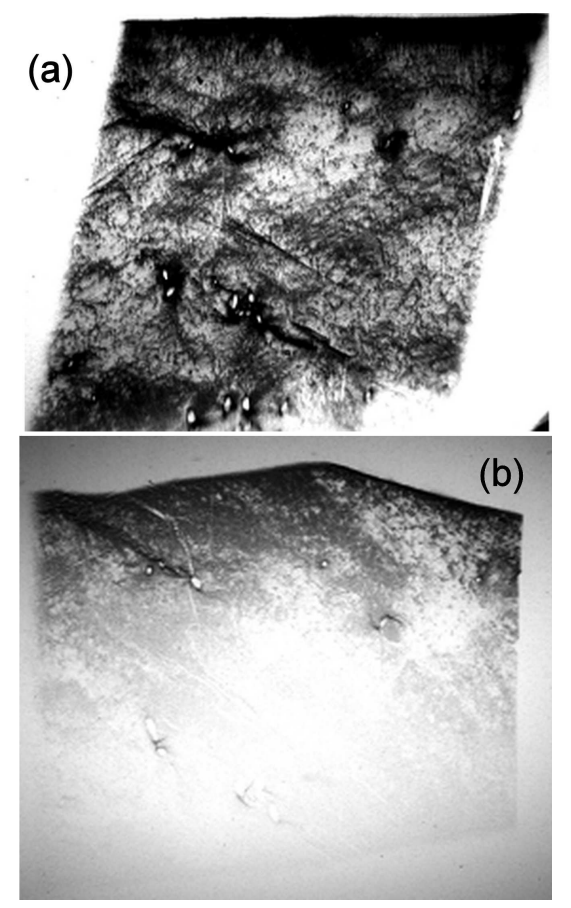

Fig. 6. Synchrotron white beam projection (a) and section (b) topographs of the sample of $4 \mathrm{H}-\mathrm{SiC}$ polytype with $8^{\circ}$ off-cut, finished by means of ECMP, with $20 \mu \mathrm{m}$ thick $\mathrm{SiC}$ epitaxial layer manufactured at the IEMT.

to $\sigma=0.22 \pm 0.07 \mathrm{~nm}$ by the appropriate initial high temperature etching.

The synchrotron topographic investigation indicated that the not perfect surface finishing led to formation of defects and strains in deposited epitaxial layers. For the sample with $4 \mathrm{H}-\mathrm{SiC}$ homoepitaxial layer grown on the substrate with $4^{\circ}$ oof-cut manufactured by SiCrystal we observed a characteristic grain-like contrast and a broadening of the reflection curves.

\section{Acknowledgments}

The synchrotron investigations were supported by the HASYLAB project II-20060165 EC.

\section{References}

[1] C. Li, I.B. Bhat, R. Wang, J. Seiler, J. Electron. Mat. 33, 481 (2004).

[2] B. Stanglmeier, W. Lenger, W. Weber, H. Göbel, M. Schuster, Acta Cryst. A 48, 626 (1992).

[3] M. Kikuchi, Y. Takahashi, T. Suga, S. Suzuki, Y. Bando, J. Amer. Ceram. Soc. 75, 189 (2005).

[4] L. Zhou, V. Audurier, P. Pirouz, J. Elecrochem. Soc. 144, 161 (1997).

[5] M. Servidori, R. Fabbri, J. Phys. D, Appl. Phys. 26, A22 (1993).

[6] H. Jacobson, J. Birch, R. Yakimova, M. Syväjävri, M. Bergman, A. Ellison, T. Tuomi, E. Janzen, J. Appl. Phys. 91, 6354 (2002). 
[7] T. Ohno, H. Yamaguchi, S. Kuroda, K. Kojima, T. Suzuki, K. Arrai, J. Cryst. Growth 260, 209 (2004).

[8] H. Tsuchida, I. Kaamata, M. Nagano, J. Cryst. Growth 310, 757 (2008).

[9] X. Zheng, M. Skowronski, K.X. Liu, R.E. Stahlbush, J.J. Sumakeris, M.J. Paisley, M.J.O. Loughin, J. Appl. Phys. 102, 093520 (2007).
[10] J. Sass, S. Jedynak, private communication.

[11] P. Caban, K. Kosciewicz, W. Strupinski, M. Wojcik, J. Gaca, J. Szmidt, M. Ozturk, E. Ozbay, J. Cryst. Growth 310, 4876 (2008). 